\title{
Labour force participation and the cost of lost productivity due to cancer in Australia

Nicole Bates ${ }^{1 *} \mathbb{D}$, Emily Callander ${ }^{2}$, Daniel Lindsay ${ }^{1,2}$ and Kerrianne Watt $^{1}$

\begin{abstract}
Background: In Australia, 40\% of people diagnosed with cancer will be of working age (25-64 years). A cancer diagnosis may lead to temporary or permanent changes in a person's labour force participation, which has an economic impact on both the individual and the economy. However, little is known about this economic impact of cancer due to lost productivity in Australia. This paper aims to determine the labour force participation characteristics of people with cancer, to estimate the indirect cost due to lost productivity, and to identify any inequality in the distribution of labour force absence in Australia.

Methods: This study used national cross-sectional data from the 2015 Survey of Disability, Ageing and Carers, conducted by the Australian Bureau of Statistics (ABS). The ABS weighted each component of the survey to ensure the sample represented the population distribution of Australia. The analysis was limited to people aged 25-64 years. Participants were assigned to one of three health condition groups: 'no health condition', 'cancer', and 'any other long-term health condition'. A series of logistic regression models were constructed to determine the association between health condition and labour force participation.

Results: A total of 34,393 participants surveyed were aged 25-64 years, representing approximately 12,387,800 Australians. Almost half (46\%) of people with cancer were not in the labour force, resulting in a reduction of $\$ 1.7$ billion to the Australian gross domestic product (GDP). Amongst those in the labour force, people with no health condition were 3.00 times more likely to be employed full-time compared to people with cancer $(95 \% \mathrm{Cl} 1.96-4.57)$ , after adjusting for age, sex, educational attainment and rurality. Amongst those with cancer, people without a tertiary qualification were 3.73 times more likely to be out of the labour force $(95 \% \mathrm{Cl} 1.97-7.07)$.

Conclusions: This paper is the first in Australia to estimate the national labour force participation rates of people with cancer. People with cancer were less likely to be in the labour force, resulting in a reduction in Australia's GDP. Cancer survivors, especially those without a tertiary qualification may benefit from support to return to work after a diagnosis.
\end{abstract}

Keywords: Cancer, Oncology, Costs, Health economics, Productivity

\section{Background}

Cancer is the leading burden of disease in Australia [1] and internationally [2]. In 2017, an estimated 134,174 Australians will be diagnosed with cancer, of which $40 \%$ will be of working age (25-64 years) [3]. Using the 2003 Survey of Disability, Ageing and Carers, Schofield et al. [4] found that half (49\%) of older Australians (aged 45-64 years) with cancer were not in the labour force.

\footnotetext{
* Correspondence: Nicole.bates@my.jcu.edu.au

${ }^{1}$ College of Public Health, Medical and Veterinary Sciences, James Cook University, Building 48, Douglas Campus, Townsville City, Queensland 4811, Australia

Full list of author information is available at the end of the article
}

In a more recent Australian study of 255 cancer patients, $67 \%$ reported changes to their employment [5]. A systematic literature review of employment and work-related issues in cancer survivors included 64 international studies and found that over a six-year period after a cancer diagnosis, $26-53 \%$ of cancer survivors were out of work (lost their job or quit) [6]. Similarly, a recent meta-analysis of international studies found that compared to healthy control participants, cancer survivors were 1.4 times more likely to be unemployed [7]. These studies focus on the individual perspective, and highlight the important financial distress faced by individual cancer patients and their 
families due to being out of the labour force [5, 8-12]. However, to date there has been minimal focus on the societal perspective in Australia, and the consideration of the aggregate costs of these changes in workforce participation; nor has there been consideration of the distribution of the costs of labour force absence, looking at the population groups most likely to be affected. Such information could be more useful to policy makers, concerned with maximising welfare to the whole of society.

Health economic evaluations routinely evaluate the direct cost of illness; however, the indirect cost of lost productivity due to morbidity and premature mortality may exceed the direct costs of cancer [13-17]. In Europe, the estimated cost of lost productivity from cancer in 2009 was $42 \%$, a further $18 \%$ was attributed to the cost of informal care, and only $41 \%$ of costs were attributed to direct health care [18]. The National Institute of Health estimated that in 2010, the cost of lost productivity in the United States accounted for $61 \%$ of the total cost of cancer, compared to $39 \%$ for the direct costs [15]. In Korea, the estimated morbidity and premature mortality costs accounted for $55 \%$ of the total cost of cancer, compared to $28 \%$ for medical care in 2009 [17]. In New South Wales, Australia in 2005, lost productivity accounted for $54 \%$ of the total lifetime cost of cancer, compared to the direct costs which accounted for $29 \%$ of the total lifetime costs [13]. However, this report was from a single state in Australia. Carter, Schofield and Shrestha [19] recently estimated that approximately 88,000 working years were lost, due to premature deaths from cancer in 2003 in Australia, which cost $\$ 4.2$ billion in present value of lifetime income. Lung and colorectal cancers accounted for $30 \%$ of the total loss of income. This study provides a national perspective of the cost of cancer due to premature mortality; however, there is currently limited work on the productivity cost for people with cancer who are out of the labour force.

This paper will contribute to the growing body of research on the indirect costs of cancer. The aims of this research conducted within an Australian context are to: 1) determine whether people with cancer have different labour force participation characteristics to people with no health conditions, or any other long term health conditions, 2) estimate the cost of cancer due to lost productivity (limited to the context of paid work) and 3) identify any inequality in the distribution of labour force absence amongst those with cancer.

\section{Methods}

Data

The primary data source accessed for this data was the 2015 Survey of Disability, Ageing and Carers (SDAC). This is a national survey conducted every 3 years by the Australian Bureau of Statistics (ABS). The SDAC sample was a randomly selected sample of the Australian population, regardless of health condition or disability status and included participants from both household and cared-accommodation, but excluded those residing in prisons/correctional institutes, religious and/or educational institutes; very remote areas, and discrete Indigenous communities. The sample frame comprised approximately 25,500 private dwellings, 250 self-care retirement, and a further 1000 cared-accommodation facilities. To adjust for any potential bias in survey participants, the ABS weight the survey data against known population benchmarks. Briefly, the weight value indicates how many of the population unit each sample unit represents. The two components were weighted separately, the household component was benchmarked to the estimated resident population in each jurisdiction, and the cared accommodation component was benchmarked to the census population counts of this component as described in detail by the ABS [20]. Weighting allows an inference of results to the general Australian population.

The survey included questions on demographics (such as age, sex, highest level of education achievement, and geographical remoteness), labour force participation, and long-term health conditions (LTHC). LTHC's were defined by the SDAC as a condition lasting, or was likely to last 6 months or more, or symptoms in the previous 12 months for an episodic condition (ie asthma or epilepsy) and coded by the ABS based upon the ICD-10 [20]. Although the original survey included answers for specific medical conditions, the ABS regrouped some conditions for data release. For example, the types of cancer were grouped by the ABS: skin cancer (ICD C43-44), breast cancer (ICD C50), prostate cancer (C61), bowel/ colorectal cancers $(\mathrm{C} 18-21)$ and any other neoplasm (including benign tumours).

\section{Statistical analysis}

Analyses were limited to people aged 25-64 years. Excluding survey respondents under the age of 25 allowed those most likely to be participating in higher education to be excluded; and those over the age of 65 were excluded, as the traditional retirement in Australia in 2015 was 65 years. Participants were categorised into one of three health condition groups: 'no LTHC' included those who did not report any LTHC, 'cancer' included those who reported having cancer (skin, breast, prostate, bowel/colorectal or any other neoplasm) as a LTHC, and 'any other LTHC' included those who reported any other LTHC. Labour force participation (LFP) was recorded as employed full-time (FT), employed part-time (PT), unemployed but looking for FT and/or PT work, and not in the labour force (NILF). ${ }^{1}$ Educational attainment was recoded into a dichotomous variable (tertiary vs non-tertiary education); as was rurality (major cities and other), and age (25-44 years and $45-64$ years). 
Aim 1: Labour force participation of people with cancer A series of logistic regression models were constructed to determine the association between cancer and LFP. Initially, the analysis was limited to include those in the labour force only. A logistic regression model was constructed to estimate the odds of being employed full-time for people with cancer, LTHC, and no health condition (respectively), after adjusting for age, sex, educational attainment and rurality. A second logistic regression model was constructed to estimate the odds of being out of the labour force for people with cancer, LTHC, and no health condition (respectively), after adjusting for age, sex, educational attainment and rurality.

\section{Aim 2: Cost of labour force absence associated with cancer}

Using the same approach as other Australian studies [21-25], the financial impact to Australia's gross domestic product (GDP) due to people with cancer being out of the labour force was estimated using the Australian Treasury's formula [26]:

$$
\begin{aligned}
\mathrm{GDP}= & (\mathrm{GDP} / \mathrm{H}) \times(\mathrm{H} / \mathrm{EMP}) \times(\mathrm{EMP} / \mathrm{LF}) \\
& \times(\mathrm{LF} / \text { Pop } 15+) \times \text { Pop } 15+
\end{aligned}
$$

where $\mathrm{GDP}=$ gross domestic product; $\mathrm{H}=$ total hours worked; EMP = total number of persons employed; LF = total labour force; and Pop15+ = population aged 15 years and over [26].

This method has been previously used in other studies [21-25], and differs from the friction cost method, which argues that people who leave the labour force due will be replaced by other workers (including those who were previously unemployed) thus limiting the cost of workers leaving the labour force [27]. Australia has a very low unemployment rate (6.3\% in July 2015) [28] and significant labour shortages in some industries [29], furthermore, the Australian Treasury's aim to make Australia's financial position more sustainable by promoting productivity, population growth and labour force participation [30], recognising the signficiant cost labour force exit has on the Australian economy.

\section{Aim 3: Inequality in the distribution of labour force absence amongst those with cancer}

A concentration index was initially used to determine whether there was any inequality in the distribution of labour force absence amongst people with cancer. The concentration index is normally used as a measure of health inequality, and assesses the distribution of health outcomes across socioeconomic groups in a population. The concentration index reflects the cumulative proportion of health held by the cumulative proportion of the population, ranked by a measure of socioeconomic status. The measure of socioeconomic status used was the highest level of education attainment achieved, as reported in the survey (7 ordinal categories: Year 8 or below, Year 10, Year11/12, Certificate, Diploma, Bachelor, Post-graduate). The concentration index ranges from -1 to 1 , with a value of 0 denoting perfect equality in the distribution of labour force absence, a negative value denoting a distribution skewed towards people of lower socioeconomic status, and a positive value denoting a distribution skewed towards people of higher socioeconomic status. The concentration index (CI), and it's associated 95\% confidence intervals, were computed as follows:

$$
2 \sigma_{R}^{2}\left(\frac{y_{i}}{\mu}\right)=\alpha+\beta R_{i}+\varepsilon_{i}
$$

Where $\sigma_{R}^{2}$ is the variance of $R_{i}$ (the individual's rank), $y_{i}$ is the labour force status of each individual $(i=1,2$, $3 \ldots . . \mathrm{N}), \alpha$ is the intercept, $\varepsilon_{i}$ is the error terms, and $\beta$ is the $\mathrm{CI}^{1}$. Finally, among only people with cancer, a multivariate logistic regression model was constructed to estimate the odds of being not in the labour force, after accounting for age, sex, educational attainment, and rurality.

All analyses were undertaken using SAS V9.4 (SAS Institute Inc., Cary, NC, USA). Weighted estimates are presented, unless stated otherwise. GDP figures are presented in 2015 Australian dollars.

\section{Results}

Within the 2015 SDAC, a total of 34,393 participants were of working age (25-64 years), which represented approximately $12,387,800$ people when weighted. Of the participants in this age group, there were $7,287,100$ with no health conditions, 108,900 people with a type of cancer, and 4,991,800 with some other LTHC. Table 1 shows the demographic characteristics for each of the health condition categories (no LTHC, cancer, and any other LTHC).

\section{Aim 1: Labour force participation of people with cancer}

Table 2 shows the employment status for people with no health condition, people with cancer, and people with any other LTHC. Almost half (46\%) of people with cancer were not in the labour force, compared to approximately a quarter $(27 \%)$ of people with any other LTHC, and only $12 \%$ of people with no health condition.

Firstly, the analyses were limited to people who were in the labour force. Of those with cancer who were employed, $47 \%$ were employed full time, compared with $68 \%$ of those with any other LTHC, and $74 \%$ of those with no health condition. Amongst those in the labour force, after adjusting for age, sex, educational attainment and rurality, those with no health condition had 3.00 
Table 1 SDAC sample demographic characteristics of Australian adults of working age, 25-64 years (using weighted totals, rounded to the nearest 100)

\begin{tabular}{|c|c|c|c|}
\hline & \multicolumn{3}{|c|}{ Long-term health condition } \\
\hline & $\begin{array}{l}\text { No LTHC } \\
\text { Total (\%) }\end{array}$ & $\begin{array}{l}\text { Cancer } \\
\text { Total (\%) }\end{array}$ & $\begin{array}{l}\text { Any other LTHC } \\
\text { Total (\%) }\end{array}$ \\
\hline \multicolumn{4}{|l|}{ Total } \\
\hline Survey Participants & 18,990 & 355 & 15,048 \\
\hline Weighted Population estimate & $7,287,100$ & 108,900 & $4,991,800$ \\
\hline \multicolumn{4}{|l|}{ Sex (weighted) } \\
\hline Male & $\begin{array}{l}3,641,800 \\
50 \%\end{array}$ & $\begin{array}{l}46,600 \\
43 \%\end{array}$ & $\begin{array}{l}2,420,400 \\
48 \%\end{array}$ \\
\hline Female & $\begin{array}{l}3,645,300 \\
50 \%\end{array}$ & $\begin{array}{l}62,300 \\
57 \%\end{array}$ & $\begin{array}{l}2,571,500 \\
52 \%\end{array}$ \\
\hline \multicolumn{4}{|l|}{ Age (weighted) } \\
\hline $25-44$ years & $\begin{array}{l}4,615,600 \\
63 \%\end{array}$ & $\begin{array}{l}18,500 \\
17 \%\end{array}$ & $\begin{array}{l}1,960,200 \\
39 \%\end{array}$ \\
\hline $45-64$ years & $\begin{array}{l}2,671,500 \\
37 \%\end{array}$ & $\begin{array}{l}90,400 \\
83 \%\end{array}$ & $\begin{array}{l}3,031,700 \\
61 \%\end{array}$ \\
\hline \multicolumn{4}{|l|}{ Educational attainment (weighted) } \\
\hline Non-tertiary & $\begin{array}{l}4,429,000 \\
62 \%\end{array}$ & $\begin{array}{l}75,500 \\
71 \%\end{array}$ & $\begin{array}{l}3,526,200 \\
73 \%\end{array}$ \\
\hline Tertiary & $\begin{array}{l}2,702,000 \\
38 \%\end{array}$ & $\begin{array}{l}30,100 \\
29 \%\end{array}$ & $\begin{array}{l}1,336,700 \\
27 \%\end{array}$ \\
\hline \multicolumn{4}{|l|}{ Rurality (weighted) } \\
\hline Major cities & $\begin{array}{l}5,610,800 \\
77 \%\end{array}$ & $\begin{array}{l}74,500 \\
68 \%\end{array}$ & $\begin{array}{l}3,425,500 \\
69 \%\end{array}$ \\
\hline Other areas & $\begin{array}{l}1,676,200 \\
23 \%\end{array}$ & $\begin{array}{l}34,400 \\
32 \%\end{array}$ & $\begin{array}{l}1,566,300 \\
31 \%\end{array}$ \\
\hline
\end{tabular}

LTHC long-term health condition

times the odds of being employed full-time than people with cancer (95\% CI 1.96-4.57; $p<0.0001)$. Similarly, those with any other LTHC had 2.15 times the odds of being employed full-time (95\% CI 1.41-3.28; $p=0.0004$ ) than those with cancer.

Secondly, the odds of being out of the labour force were calculated. Table 3 shows that after adjusting for age, sex, educational attainment and rurality, those with

Table 2 Labour force participation of participants (weighted) ${ }^{\text {a }}$

\begin{tabular}{lllll}
\hline $\begin{array}{l}\text { Health } \\
\text { condition }\end{array}$ & $\begin{array}{l}\text { Employed FT } \\
\text { Number (\%) }\end{array}$ & $\begin{array}{l}\text { Employed PT } \\
\text { Number (\%) }\end{array}$ & $\begin{array}{l}\text { NILF } \\
\text { Number (\%) }\end{array}$ & $\begin{array}{l}\text { Total weighted } \\
\text { population } \\
\text { estimate }\end{array}$ \\
\hline No LTHC & $4,585,900$ & $1,589,700$ & 887,100 & $7,287,000$ \\
& $62.9 \%$ & $21.8 \%$ & $12.2 \%$ & \\
Cancer & 27,300 & 30,400 & 50,100 & 108,100 \\
& $25.3 \%$ & $28.1 \%$ & $46.4 \%$ & \\
Any other & $2,328,700$ & $1,104,900$ & $1,344,100$ & $4,975,900$ \\
LTHC & $46.8 \%$ & $22.2 \%$ & $27.0 \%$ & \\
\hline
\end{tabular}

LTHC long-term health condition, FT full-time, PT part-time, NILF not in the labour force, have not looked for work in the last 4 weeks, and do not intend to work or look for work in the future

${ }^{\text {a }}$ The number and percentage of people who were 'unemployed' were not presented due to low unemployment rate in Australia, and hence the low sample number of unemployed people
Table 3 Logistic regression model of being not in the labour force

\begin{tabular}{llll}
\hline Parameter & Estimate & Standard Error & $P$-Value \\
\hline Intercept & -2.49 & 0.16 & $<0.001$ \\
Male & 0.97 & 0.35 & $<0.001$ \\
Aged 25-44 & 0.35 & 0.03 & $<0.001$ \\
Tertiary education attainment & 0.70 & 0.04 & $<0.001$ \\
Lives in major city & 0.04 & 0.04 & 0.2255 \\
No LTHC & -1.68 & 0.14 & $<0.001$ \\
Any other LTHC & -0.81 & 0.14 & $<0.001$
\end{tabular}

Odds of being out of the labour force

\begin{tabular}{llll} 
& $\begin{array}{l}\text { Odds Ratio }^{\mathrm{a}} \\
\text { Cancer }\end{array}$ & $95 \% \mathrm{Cl}$ & $P$-value \\
No LTHC & 0.19 & $0.14-0.25$ & $<0.001$ \\
Any other LTHC & 0.45 & $0.34-0.58$ & $<0.001$ \\
\hline
\end{tabular}

LTHC long-term health condition

adjusted $\mathrm{OR}=$ adjusted for age, sex, educational attainment, and rurality

no health condition, and those with any other long-term health condition had lower odds of being out of the labour force compared to adults with cancer.

\section{Aim 2: Cost of labour force absence associated with cancer}

An estimated 50,100 Australian adults of working age (25-64 years) with cancer were not in the labour force in 2015, thereby reducing Australia's GDP by approximately $\$ 1.7$ billion (Table 4 ).

Table 4 The proportion of people out of the labour force, and the financial impact on Australia's GDP amongst people with cancer (weighted)

\begin{tabular}{|c|c|c|c|c|}
\hline & $\begin{array}{l}\text { Estimated } \\
\text { number } \\
\text { NILF }\end{array}$ & $\begin{array}{l}\text { Total people } \\
\text { with cancer }\end{array}$ & $\begin{array}{l}\% \text { NILF/total } \\
\text { people with } \\
\text { cancer }\end{array}$ & $\begin{array}{l}\text { Difference } \\
\text { in GDP AU\$ } \\
\text { million }\end{array}$ \\
\hline \multicolumn{5}{|l|}{$\overline{\text { Total }}$} \\
\hline & 50,100 & 108,900 & $46 \%$ & $\$ 1738$ million \\
\hline \multicolumn{5}{|l|}{ Sex } \\
\hline Male & $19900^{a}$ & 46,600 & $43 \%$ & $\$ 690$ million \\
\hline Female & $30300^{a}$ & 62,300 & $49 \%$ & $\$ 1051$ million \\
\hline \multicolumn{5}{|l|}{ Age } \\
\hline $25-44$ years & 6900 & 18,500 & $37 \%$ & $\$ 239$ million \\
\hline 45-64 years & 43,200 & 90,400 & $48 \%$ & \$1499 million \\
\hline \multicolumn{5}{|c|}{ Educational attainment } \\
\hline Non-tertiary & 42,100 & 75,500 & $56 \%$ & $\$ 1460$ million \\
\hline Tertiary & 7500 & 30,100 & $25 \%$ & $\$ 260$ million \\
\hline \multicolumn{5}{|l|}{ Rurality } \\
\hline Major cities & 32,100 & 74,500 & $43 \%$ & $\$ 1114$ million \\
\hline Other areas & 18,000 & 34,400 & $52 \%$ & $\$ 624$ million \\
\hline
\end{tabular}

arounded up 


\section{Aim 3: Inequality in the distribution of labour force absence amongst those with cancer}

The concentration index showing level of inequality in the distribution of labour force absence amongst people with cancer was calculated to be -0.20 (95\% CI -0.26 to -0.13), which indicates that having cancer and being not in the labour force is unequally skewed towards those with a low educational attainment.

Amongst people with cancer, those without a tertiary qualification were 3.73 times more likely to be out of the labour force (95\% CI 1.97-7.07; $p<0.0001$ ), than people with tertiary education. Sex, age, and rurality were not associated with being out of the labour force $(p=0.0818$, $p=0.3723, p=0.1869$ respectively).

\section{Discussion}

The results of this paper have shown that in 2015, almost half (46\%) of adults of working age (25 to 64 years) with cancer were not in the labour force. Of those in the labour force, adults with no health conditions had 3 times the odds of being employed full-time than adults with cancer. Other studies have supported our findings that following a cancer diagnosis, many patients report a temporary or permanent change to their labour force participation, including a reduction in work hours and stopping work $[5,6,8,9,11,31-34]$.

Amongst people with cancer, a greater proportion of older people (45-64 years) were not in the labour force, however, this appears to be explained by other demographic factors. Amongst people with cancer, those without a tertiary qualification had nearly four times the odds of being out of the labour force; age, sex, and rurality were not associated with a greater risk. Higher education attainment has been identified as a positive factor in returning to work [6,35], which also supports our findings that labour force absence amongst those with cancer is unequally skewed towards those with lower levels of education attainment. Other factors which may affect returning to work include jobs that require manual labour, and those with less flexible working arrangements $[6,8,10,32,33]$. The type of cancer and treatment factors may also negatively impact returning to work $[6,7,10,35]$. For example, Clarke et al. [35] found that colorectal and lung cancer survivors had greater difficulties performing daily activities, and colorectal, lung, and bladder cancer survivors were more likely to have functional limitations, which may impact work ability.

This paper looked at distribution of people being out of the labour force for any reason, with some people potentially being out of the labour force directly as a result of cancer, while others may have chosen early retirement [11] due to a reassessment of their priorities following a health shock. In Australia, employees (excluding casual employees) are entitled to paid sick leave (10 days each year for full-time employees), and unpaid leave for up to 3 months [36]. While the Australian retirement age in 2015 was 65 years, at which time individuals may be eligible to access a government 'age pension', individuals may have access to their superannuation from age 55 . However, previous work has found that despite these sources of financial support, early retirement due to LTHC has a significant negative impact on an individual's income and wealth $[22,25]$. As such cancer survivors may benefit from additional support by the Government, employers and medical professionals to facilitate returning to work if they choose to. Previous studies have shown that many cancer survivors will return to work after treatment, from $40 \%$ at six-months to $89 \%$ at 24 -months following a cancer diagnosis [6].

A key strength of this paper is that it used the 2015 SDAC, which is a national survey weighted to the Australian population. Participants who identified as having cancer as a long-term health condition represented $0.9 \%$ of the weighted population. It was estimated that around $1.5 \%$ of the Australian population had cancer in 2011-12 [37]. However, we limited our analyses to people of working age only (25-64 years), which excluded people over 75 years, who had the highest rate of developing cancers (11.1\% for men and $4.4 \%$ for women) [37]. Therefore, this study was representative of the Australian population of working age.

However, the use of the SDAC also has several limitations. This survey did not include information about the time since diagnosis, which may be a factor in labour force participation $[8,9,12]$. Secondly, although the main types of cancer in Australia (skin, breast, prostate, and colorectal cancer) are identified in the SDAC, the number of participants in each type was small, and therefore, disaggregated analysis by type of cancer was not possible. Finally, it is possible that some types of cancers, which may have minimal impacts on returning to work, may have been over-estimated, particularly if someone recently had the lesion removed. For example, non-melanoma skin cancers are the most common type of cancer in Australia, and in some cases, the cancer is completely removed with a biopsy, or removed by surgical excision [38, 39]. We only included LTHC in our analyses, which was defined in the survey as conditions lasting or expected to last 6-months [20], which should exclude cases in which the only treatment received was complete removal of the lesion.

This paper provides an insight into the economic burden of cancer due to labour force participation, and builds upon the growing body of literature. However, we acknowledge that this is only a small part of the larger burden of cancer, and are currently conducting a larger study on the cost of cancer to the healthcare system and the individual [40]. Future research also should look at 
the distribution of labour force participation rates across the different types of cancer to ensure equitable access and allocation of resources.

\section{Conclusion}

A large proportion of Australians diagnosed with cancer are of working age, and in general cancer survival rates are improving [3]. Furthermore, in light of the increase of the Australian retirement age, from the current 65 to 67 years by 2023 (increasing by 6 months every 2 years commencing July 2017 [41]), it is reasonable to expect that the cost of lost productivity may increase in the coming years. There is a call for support systems to facilitate return to work for cancer survivors who want to work [42]. For some survivors, returning to work after a cancer diagnosis is an important milestone, both financially and emotionally $[33,43]$. Cancer survivors without a tertiary qualification may benefit from additional support. This paper is the first in Australia to estimate the national labour force participation rates of adults of working age with cancer, and the indirect cost of cancer due to lost productivity. This information is valuable when considering how cancer affects patients and society.

\section{Endnote}

${ }^{1}$ Not in the Labour Force defined as not in the labour force, and have not looked for work in the last 4 weeks, and do not intend on working or looking for work in the future.

\section{Abbreviations}

ABS: Australian Bureau of Statistics; Cl: Concentration index; FT: Full-time; GDP: Gross domestic profit; LFP: Labour force participation; LTHC: Long-term health condition; NILF: Not in the labour force; PT: Part-time; SDAC: Survey of Disability, Ageing and Carers

\section{Acknowledgements}

Not applicable.

\section{Funding}

Part of Dr Callander's salary comes from a National Health and Medical Research Council (NHMRC) Early Career Fellowship (APP1052742). This funding body had no role in the design of the study and collection, analysis, interpretation of data, or in writing the manuscript.

\section{Availability of data and materials}

The data that support the findings of this study are available upon request from the Australian Bureau of Statistics.

\section{Authors' contributions \\ NB and EC conceived the study, participated in study design, performed the analyses, contributed to the interpretation, and writing the manuscript. DL participated in interpreting the results, and writing the manuscript. KW participated in the design of the study and writing of the manuscript. All authors have read and approved the final manuscript.}

\section{Ethics approval and consent to participate}

The dataset for this study is from publicly, de-identified available data, with permission from the Australian Bureau of Statistics.

Consent for publication

Not applicable

\section{Competing interests}

The authors declare that they have no competing interests.

\section{Publisher's Note}

Springer Nature remains neutral with regard to jurisdictional claims in published maps and institutional affiliations.

\section{Author details}

${ }^{1}$ College of Public Health, Medical and Veterinary Sciences, James Cook University, Building 48, Douglas Campus, Townsville City, Queensland 4811, Australia. ${ }^{2}$ Australian Institute of Tropical Health and Medicine (AITHM), James Cook University, Townsville, Queensland 4811, Australia.

Received: 18 May 2017 Accepted: 12 March 2018

Published online: 06 April 2018

\section{References}

1. Australian Institute of Health and Welfare (AIHW). Australian burden of disease study: impact and causes of illness and death in Australia 2011. In: Australian burden of disease study series no 3 BOD 4. Canberra: AlHW; 2016.

2. Ferlay J, Soerjomataram I, Dikshit R, Eser S, Mathers C, Rebelo M, Parkin DM, Forman D, Bray F. Cancer incidence and mortality worldwide: sources, methods and major patterns in GLOBOCAN 2012. Int J Cancer. 2015;136(5): E359-86.

3. Australian Institute of Health and Welfare (AIHW). Cancer in Australia 2017. In: Cancer series no 101 cat no CAN 100. Canberra: AlHW; 2017.

4. Schofield DJ, Shrestha RN, Passey ME, Earnest A, Fletcher SL. Chronic disease and labour force participation among older Australians. Med J Aust. 2008; 189(8):447-50.

5. Paul C, Boyes A, Hall A, Bisquera A, Miller A, O'Brien L. The impact of cancer diagnosis and treatment on employment, income, treatment decisions and financial assistance and their relationship to socioeconomic and disease factors. Support Care Cancer. 2016;24(11):4739-46.

6. Mehnert A. Employment and work-related issues in cancer survivors. Crit Rev Oncol Hematol. 2011;77(2):109-30.

7. de Boer AG, Taskila T, Ojajarvi A, van Dijk FJ, Verbeek JH. Cancer survivors and unemployment: a meta-analysis and meta-regression. JAMA. 2009; 301(7):753-62

8. Gordon LG, Beesley VL, Lynch BM, Mihala G, McGrath C, Graves N, Webb PM. The return to work experiences of middle-aged Australian workers diagnosed with colorectal cancer: a matched cohort study. BMC Public Health. 2014;14:963.

9. Gordon L, Scuffham P, Hayes S, Newman B. Exploring the economic impact of breast cancers during the 18 months following diagnosis. Psychooncology. 2007:16(12):1130-9.

10. Spelton ER, Sprangers MA, Verbeek JH. Factors reported to influence the return to work of cancer survivors: a literature review. Psychooncology. 2002;11:124-31.

11. Gordon LG, Walker SM, Mervin MC, Lowe A, Smith DP, Gardiner RA, Chambers SK. Financial toxicity: a potential side effect of prostate cancer treatment among Australian men. Eur J Cancer Care (Engl). 2017;26(1): e12392. doi:https://doi.org/10.1111/ecc.12392

12. Bradley CJ, Neumark D, Oberst K, Luo Z, Brennan S, Schenk M. Combining registry, primary, and secondary data sources to identify the impact of cancer on labor market outcomes. Med Decis Mak. 2005;25(5):534-47.

13. Access Economics. Cost of cancer in NSW. Cancer Institute of NSW: Sydney; 2007.

14. Jonsson B, Wilking N. The burden and cost of cancer. Ann Oncol. 2007; 18(Supplement 3):8-22.

15. American Cancer Society. Cancer facts and figures 2011, vol. 3. Atlanta: American Cancer Society; 2011

16. Sullivan R, Peppercorn J, Sikora K, Zalcberg J, Meropol NJ, Amir E, Khayat D, Boyle P, Autier P, Tannock IF, et al. Delivering affordable cancer care in high-income countries. Lancet Oncol. 2011;12(10):933-80.

17. Kim SY, Park JH, Kang KH, Hwang I, Yang HK, Won YJ, Seo HG, Lee D, Yoon SJ. The economic burden of cancer in Korea in 2009. Asian Pac J Cancer Prev. 2015;16(3):1295-301.

18. Luengo-Fernandez R, Leal J, Gray A, Sullivan R. Economic burden of cancer across the European Union: a population-based cost analysis. Lancet Oncol. 2013;14(12):1165-74 
19. Carter HE, Schofield DJ, Shrestha R. The productivity costs of premature mortality due to cancer in Australia: evidence from a microsimulation model. PLoS One. 2016;11(12):e0167521.

20. Australian Bureau of Statistics (ABS). Disability, ageing and Carers, Australia: first results, 2015. In: ABS cat no 4430010001. Canberra: ABS; 2016.

21. Schofield D, Cunich MM, Shrestha RN, Passey ME, Veerman L, Callander EJ, Kelly SJ, Tanton R. The economic impact of diabetes through lost labour force participation on individuals and government: evidence from a microsimulation model. BMC Public Health. 2014;14:220.

22. Schofield DJ, Shrestha RN, Percival R, Passey ME, Callander EJ, Kelly SJ. The personal and national costs of mental health conditions: impacts on income, taxes, government support payments due to lost labour force participation. BMC Psychiatry. 2011;11:72.

23. Schofield D, Shrestha R, Percival R, Passey M, Callander E, Kelly S. The personal and national costs of CVD: impacts on income, taxes, benefits and GDP due to lost labour force participation. Int J Cardiol. 2013;166(1):68-71.

24. Schofield DJ, Shrestha RN, Percival R, Passey ME, Kelly SJ, Callander EJ. Economic impacts of illness in older workers: quantifying the impact of illness on income, tax revenue and government spending. BMC Public Health. 2011;11:418.

25. Schofield DJ, Shrestha RN, Percival R, Passey ME, Callander EJ, Kelly SJ. The personal and national costs of lost labour force participation due to arthritis: an economic study. BMC Public Health. 2013;13:188.

26. Costello P. The intergenerational report 2007, vol. 13. Canberra: Commonwealth of Australia; 2007.

27. Koopmanschap MA, Rutten FF, van Ineveld BM, van Roijen L. The friction cost method for measuring indirect costs of disease. J Health Econ. 1995; 14(2):171-89.

28. Australian Bureau of Statistics (ABS). Labour force, Australia, Jul 2015. In: ABS cat no 62020. Canberra: ABS; 2015.

29. Mitchell W, Quirk V. Skills shortages in Australia: concepts and reality. Newcastle: University of Newcastle, Centre for Full Employment and Equity; 2005.

30. Australian Treasury. The 2010 intergenerational report. Australian Government: Canberra; 2010.

31. Gordon L, Lynch BM, Newman B. Transitions in work participation after a diagnosis of colorectal cancer. Aust N Z J Public Health. 2008;32(6):569-74.

32. Mackenzie CR. 'It is hard for mums to put themselves first': how mothers diagnosed with breast cancer manage the sociological boundaries between paid work, family and caring for the self. Soc Sci Med. 2014;117:96-106.

33. McGrath PD, Hartigan B, Holewa H, Skarparis M. Returning to work after treatment for haematological cancer: findings from Australia. Support Care Cancer. 2012;20(9):1957-64.

34. Short PF, Vasey JJ, Tunceli K. Employment pathways in a large cohort of adult cancer survivors. Cancer. 2005;103(6):1292-301.

35. Clarke TC, Christ SL, Soler-Vila H, Lee DJ, Arheart KL, Prado G, Martinez AC, Fleming LE. Working with cancer: health and employment among cancer survivors. Ann Epidemiol. 2015;25(11):832-8.

36. Fair Work Ombudsman. Sick and carer's leave, Long periods of sick leave. https://www.fairwork.gov.au/leave/sick-and-carers-leave/long-periods-of-sickleave. Accessed 28 Nov 2017.

37. Australian Bureau of Statistics (ABS). Profiles of health, Australia, 2011-13. In: ABS cat no 43380, vol. 25. Canberra: ABS; 2012.

38. Australian Institute of Health and Welfare (AlHW), Cancer Australia. Nonmelanoma skin cancer: general practice consultations, hospitalisation and mortality. In: Cancer series no 43 cat no 39. Canberra: AlHW; 2008.

39. Cancer Council Australia. Non-melanoma cancer. http://www.cancer.org.au/ about-cancer/types-of-cancer/skin-cancer/non-melanoma.html. Accessed 12 July 2015.

40. Callander E, Topp SM, Larkins S, Sabesan S, Bates N. Quantifying Queensland patients with cancer health service usage and costs: study protocol. BMJ Open. 2017:7(1):e014030.

41. Department of Human Services Australian Government. Age pension. 2017. https://www.humanservices.gov.au/customer/services/centrelink/agepension. Accessed 10 March 2017.

42. Koczwara B. We need more support systems for people who want to work during and after cancer treatment, vol. 15: The Conversation; 2016.

43. McKay G, Knott V, Delfabbro P. Return to work and cancer: the Australian experience. J Occup Rehabil. 2013;23(1):93-105.

\section{Submit your next manuscript to BioMed Central and we will help you at every step:}

- We accept pre-submission inquiries

- Our selector tool helps you to find the most relevant journal

- We provide round the clock customer support

- Convenient online submission

- Thorough peer review

- Inclusion in PubMed and all major indexing services

- Maximum visibility for your research

Submit your manuscript at www.biomedcentral.com/submit
) Biomed Central 